\title{
Safety checks, monitoring and documentation in medication process in long-term elderly care-Nurses' subjective perceptions
}

\author{
Markus Karttunen*1, Sami Sneck², Jari Jokelainen ${ }^{3,4}$, Niko Männikkö ${ }^{5,6}$, Satu Elo ${ }^{7}$ \\ ${ }^{1}$ Oulu University of Applied Sciences, Oulu, Finland \\ ${ }^{2}$ Medication education and safety coordinator, Oulu University Hospital, Oulu, Finland \\ ${ }^{3}$ Unit of General Practice, Oulu University Hospital, Oulu, Finland \\ ${ }^{4}$ Center for Life Course Epidemiology and Systems Medicine, University of Oulu, Oulu, Finland \\ ${ }^{5}$ Department of Social Services and Rehabilitation, Oulu University of Applied Sciences, Oulu, Finland \\ ${ }^{6}$ Research Unit of Nursing Science and Health Management, University of Oulu, Oulu, Finland \\ ${ }^{7}$ University of Oulu, Oulu, Finland
}

Received: February 15, 2019

DOI: $10.5430 /$ jnep.v9n8p26
Accepted: April 14, 2019

Online Published: April 24, 2019

\begin{abstract}
Objective: Elderly people often use several medicines, which increases risks for side effects and adverse effects. Moreover, most reported adverse events in healthcare are associated with medication. The aim was to describe nursing staffs' perceptions about and the factors related to the actualization of safety checks, monitoring and documentation in the medication process in long-term elderly care.

Methods: This was a cross-sectional quantitative, questionnaire-based study. The response rate, among all nurses working in long-term elderly care wards in a Finnish healthcare district, was 39.4\% ( $\mathrm{n}=492)$.

Results: The results indicate that some safety checks and monitoring guidelines are often violated during the medication administration process, but most nurses self-reportedly maintained good practice in medication documentation.

Conclusions: The results suggest needs to review training in pharmacology, infection control, and medication calculations during pre-qualification and continuing education, and to ensure nurses' awareness of attitudes and ethical considerations for medication safety.
\end{abstract}

Key Words: Medication safety, Checks, Monitoring, Documentation, Nursing, Elderly care

\section{BACKGROUND}

Medication is an essential part of elderly care. According to WHO statistics, life expectancy is continuously increasing, so morbidity is also increasing. Hence, old people often use several medicines simultaneously, and through medication the patient should receive more benefit than discomfort. However, polypharmacy increases risks for side and adverse effects. ${ }^{[1-3]}$ Moreover, there is a high prevalence of risk factors in the medication process of elderly people, ${ }^{[2]}$ hence reducing the occurrence of medication errors in their nursing is particularly challenging.

According to the American Society of Health-System Pharmacists (ASHP) the medication process consists of five steps: (a) ordering/prescribing, (b) transcribing and verify-

*Correspondence: Markus Karttunen; Email: markus.karttunen@oamk.fi; Address: Oulu University of Applied Sciences, Oulu, Finland. 
ing, (c) dispensing and delivering, (d) administering, and (e) monitoring and reporting. ${ }^{[4]}$ Nurses are primarily involved in the administering stage, which also includes preparation of the medicine, but they also participate in the dispensing, delivering, monitoring and reporting stages. Most errors in health care reportedly occur in above-described medication process ${ }^{[5,6]}$ typically during the medication administration stage. ${ }^{[6-9]}$ The wrong medication, wrong form of medicine, wrong dose, wrong timing or wrong patient are the usual types of errors. ${ }^{[6,7,9-13]}$ In addition, several studies have detected incomplete identification of patients during medication administration processes ${ }^{[7,14,15]}$ which increases risks for medication errors. Ernawati et al. ${ }^{[9]}$ found that most errors identified in the administration stage were related to documentation. In another study based on a hospital's incident reports, $21 \%$ of recorded medication incidents occurred during documentation or reading of documents, and $10 \%$ during verification of the medicines. ${ }^{[15]}$

Several factors hindering medication safety have been identified, including insufficient knowledge and lack of time, ${ }^{[16]}$ and several ways to counter them. According to previously surveyed nurses, an effective way to prevent errors is to enhance attention and caution. ${ }^{[17]}$ Another, according to Pape, ${ }^{[18]}$ is to implement protocols from other highly safetyfocused industries, e.g. the airline industry, with appropriate adaptations. This approach involves strict use of safetycheck-like 'medication rights' designed to ensure patient safety and prevent harm during the medication administration process. The safety checks should confirm that the right drug is given to the right patient, at the right dose, via the right route, at the right time in every administration. Double-checking, where two nurses independently and appropriately confirm that everything is right, is also recommended. ${ }^{[19]}$ Also most nurses surveyed by Jones \& Treiber ${ }^{[20]}$ regarded the statement 'Did not follow the 5 rights' as very important contributing factor to medication errors. Moreover, Manias ${ }^{[21]}$ found that graduate nurses only adhered to the protocols if they had enough time, and Kim $\&$ Bates $^{[22]}$ reported that many medication administration guidelines are not strictly followed. In this article, safety checks are defined as checks a nurse should perform during the medication administration process when preparing and administering medication.

A sixth right that has been added is the 'right response', or more strictly right evaluation of the effectiveness of medication, i.e., whether or not the patient receives the desired outcomes and benefits of the treatment. ${ }^{[23-25]}$ Hereafter, 'right response' is called 'right monitoring'. The Finnish National Institute for Health and Welfare ${ }^{[26]}$ has stated that effects of medication should be monitored by following the condition

Published by Sciedu Press of the patient by appropriate measurements, e.g., measurements of blood pressure, weight and relevant biochemical or genetic markers. In addition, the amounts of required medicines, and amounts patient actually use, should independently be monitored. The patient should also be asked about the medication's desired effects, adverse effects and her/his satisfaction with it. Such monitoring can be carried out by the patient, but also by all the staff involved in the nursing activities. However, for effective monitoring a nurse needs competence in medication management, which has several components. ${ }^{[27]}$ For obvious reasons, an important component is pharmacological knowledge ${ }^{[28-30]}$ but nursing students reportedly have limited knowledge of pharmacy and medication calculation skills before graduation. ${ }^{[28]}$ Therefore, this article addresses nurses' monitoring of medication in addition to the five rights listed above.

A further essential part of all nursing activities is documentation. It is crucial to document all medication activities immediately after any administration, to provide clear indications of both successes and failures. ${ }^{[9,24]}$ Thus, nurses should accurately document both medications given and their effects, as an important role of documentation is to provide evidence of possible side or adverse effects of medications. ${ }^{[26]}$ Moreover, the documentation should record any deviation from prescribed medication procedures (e.g., in administration time) including explanation for the deviation, expected responses and scheduled interventions. ${ }^{[31]}$ Thus, all documentation in the medication administration process is also considered in this article.

For reasons outlined above, the aim of the study was to elicit nursing staffs' subjective perceptions about and factors influencing the performance of safety checks, monitoring and documentation in medication process in long-term elderly care.

\section{Aim}

The aim of the study was to describe nursing staffs' perceptions about and the factors related to how safety checks, monitoring and documentation actualizes in medication process in long-term elderly care.

\section{MethodS}

\subsection{Study design}

Data were collected using a web-based questionnaire (Webropol 3.0) distributed to the total population of nurses $(\mathrm{N}=$ $1,249)$ working in all 79 communal long-term elderly care wards in one of the Finnish health care districts in November 2016. The main occupational groups within this population were registered nurses and practical nurses. In Finland, registered nurses hold Bachelor's degrees in nursing and have the 
right to administer oral and intravenous medication, and to give injections to patients; they are responsible for the overall implementation of medication prescribed by medical doctors or specially educated registered nurses. Practical nurses hold a vocational upper secondary qualification in nursing and are mainly allowed to prepare and administer enteral medication and limited parenteral medication. The minor occupational groups were Bachelors of Social Services and nursing assistants. Both these occupational groups take part in medication administration under supervision after further training. The questionnaire was sent to superiors of the wards for forwarding to other nurses. A cover letter was included in the link, which included all the necessary information, as well as a statement that participation was anonymous, voluntary and that participants could withdraw at any time without giving any reason. Reminders were sent to the nurses four times during the data collection period of one month. The questionnaire was closed four weeks after the link was first sent to the participants. The response rate was $39.4 \%(n=492)$.

The study reported here was phase III of a broader project called Safe Medication Management in Long-Term Elderly Care, which had three phases. Phase I involved development of a Safe Medication Management Scale. Phase II involved identification and analysis of safe medication preparation and administration practices in long-term elderly care. Phase III concerned safety checks, monitoring and documentation during the medication management process in long-term elderly care. Results from phases I and II have been reported in Karttunen et al. (2017) ${ }^{[32]}$ and Karttunen et al. (2019), ${ }^{[33]}$ respectively.

\subsection{The scale}

Safe Medication-Scale was developed by adapting the steps of the DeVellis' scale development process. ${ }^{[34]}$ First, a scoping literature review and a qualitative content analysis were carried out. In the process 11 divisions of safe medication (Right Action, Right Medication, Right Dose, Right Route, Right Patient, Right Preparation, Right Time, Right Counselling, Right Response, Right Documentation and Right Asepsis) were found and the items were formed based on the results of the literature review. Likert scale from 0 to 5 was chosen, and in each eleven sets, there were an open question for free text for the participants to justify their choice. A panel of experts assessed the validity of the content of the scale, then a pilot study was conducted. After the process, the scale consisted of 109 items. Tarkkonen's rho was used to estimate its reliability, which was found to be satisfactory $(>0.60)$. Details of the process can be found in Karttunen et al. $(2017)^{[32]}$ in Finnish.

Prior to analysis, the scale's 109 items were re-categorized in accordance with the ASHP stages of medication process, ${ }^{[4]}$ to facilitate process-based analysis. Eight new categories were formed: medication preparation, medication administration, asepsis in medication administration, safety checks during the medication administration process, monitoring, documentation, patient involvement and principles (covered by $10,8,7,15,8,6,14$ and 17 items, respectively). In this re-categorization, all items concerning the same stage of the medication process were grouped. Cronbach's alpha and Tarkkonen's rho values were calculated for these new categories (see Table 1). In addition to the demographic information, the scale also includes the following questions on background variables. How often do you dispense drugs? How often do you prepare medicines? How often do you administer medicines to patients? Do you have adequate knowledge base of pharmacology? Do you have adequate knowledge base of infection control? and Do you have adequate skills in medication calculations? This article reports results concerning the safety checks, monitoring and documentation categories.

Table 1. Summary statistics of the safety checks, monitoring and documentation scores, with Tarkkonen's rho and Cronbach's alpha values

\begin{tabular}{llllll}
\hline Category & Items & Tarkkonen's rho & Cronbach's $\boldsymbol{\alpha}$ & Mean & SD \\
\hline Safety Checks & 15 & 0.830 & 0.776 & 0.495 & 0.400 \\
Monitoring & 8 & 0.857 & 0.834 & 0.528 & 0.460 \\
Documentation & 6 & 0.718 & 0.578 & 0.330 & 0.361 \\
\hline
\end{tabular}

\subsection{Analysis}

Data were analyzed statistically using the Statistical Package for the Social Sciences (SPSS) version 24. At the beginning, the distributions of the variables were described. Initially, participants were grouped by age in four quartiles $(<39$ years, 39-48 years, $49-55$ years, $>55$ years), by working ex- perience in four quartiles ( $<8$ years, $8-14$ years, $15-24$ years, $>24$ years) and by education in three categories (registered nurses, practical nurses, others).

The items were scored according to the following Likert scale: 0 (Always follows the recommendations), 1 (Often 
follow the recommendation), 2 (Sometimes follow the recommendation), 3 (Rarely follow the recommendation), 4 (Never follow the recommendation), 5 (Does not apply to me), treated as a missing value. The closer the result is to zero, the better the participant implements safe medication management.

Cross tabulation and Chi-Squared tests were used to investigate associations between categorical variables. The variation among group means was analyzed using One-Way ANOVA if the data met homogeneity of variance requirements (according to Levene's test), and otherwise by the Kruskal-Wallis test. Post-hoc Bonferroni correction and Mann-Whitney U tests were respectively applied to identify categories where differences were significant when the ANOVA and Kruskal-Wallis tests detected significant differences. Summary statistics are reported as means \pm standard deviations unless otherwise stated. Significance thresholds were set at the commonly used levels of $p<.05$ (significant) and $p<.001$ (very significant).

\subsection{Ethical considerations}

There was no need for an ethical statement from the ethical committee to conduct the research since the study did not involve intervention in the integrity of a person (Medical Research Act 488/1999). The research permit was obtained from the director of elderly care of each municipality involved in the research. Participation was voluntary and participants were informed of the objectives and the methods of the study. It was interpreted as an informed consent when a participant returned the questionnaire. Responses were returned anonymously and all information about the participants was treated confidentially. The participant could not be identified at any stage of the study.

\section{RESUlts}

Most (73.5\%) of the participants were practical nurses, $18.7 \%$ were registered nurses, and the rest $(7.7 \%)$ were others like bachelors in social services, and nursing assistants. Most of the participants were female $(98 \%)$, their age varied between 18 and 64 years (mean, $46 \pm 11.1$ years), and their working experience in nursing from 0.5 to 42 years (mean, $15.9 \pm$ 10.5years) (see Table 2).

Most $(91 \%)$ of the nursing staff reportedly administered medication for patients daily (91\%). Nearly half (45\%) prepared medication daily while the rest $(55 \%)$ did it less than three times per week. Most (82\%) dispensed medication, and the same percentage stated that they always followed safe medication principles during the medication administration process. The participants were asked to evaluate on a scale from 1 to 10 how well the nursing staff in their ward gen- erally follow safe medication principles in the medication process. The registered nurses regarded this as significantly $(p<.01)$ worse than the practical nurses (scores: $8.2 \pm 0.9$ and $8.5 \pm 1.1$, respectively).

Table 2. Demographic profile of the participants $(\mathrm{N}=492)$

\begin{tabular}{lll}
\hline Variable & $\mathbf{n}$ & \% \\
\hline Sex & & \\
Male & 9 & 1.8 \\
Female & 483 & 98.2 \\
Age (years) & & \\
$<39$ & 123 & 25 \\
$39-48$ & 122 & 24.8 \\
$49-55$ & 132 & 26.8 \\
$>55$ & 115 & 23.4 \\
Nursing Education & & \\
Registered Nurse & 92 & 18.7 \\
Practical Nurse & 362 & 73.5 \\
Other & 38 & 7.7 \\
Working Experience (years) & & \\
$<8$ & 131 & 26.6 \\
$8-14$ & 118 & 24 \\
$15-24$ & 125 & 25.4 \\
$>24$ & 118 & 24 \\
\hline
\end{tabular}

\subsection{Safety checks}

Most participants $(68 \%)$ stated that they always followed safety check guidelines, but nearly a third reportedly did not always perform the recommended safety checks during the medication process, and the mean Likert score for this was $0.5 \pm 0.4$. Moreover, only $35.8 \%$ confirmed patients' identities from their wristbands, less than half (40.9\%) double-checked after medication calculations, and roughly half $(48.4 \%)$ checked that medication about to be given corresponded to the prescribed medication (see Table 3 ).

No significant differences were found among the occupational, working experience or age groups of participants in responses to items in the safety checks category. There were also no significant differences in these responses between nurses who prepared medication daily, three times a week or less often. However, significant positive correlations were found between reported habitual performance of safety checks during the medication process and the participants' self-estimated knowledge of pharmacology and infection control $(p<.001)$ and medication calculation skills $(p<.05)$ (see Table 4$)$. There was also a very significant correlation ( $p$ $<.001$ ) between good scores for items in the safety checks category (mean < 0.2) and self-reported thoroughness of following the recommendations $(9.0 \pm 0.8$, versus $8.5 \pm 0.9$ for those with poorest safety check scores). 
Table 3. Items of the safety checks category

\begin{tabular}{|c|c|c|c|}
\hline Item & $\begin{array}{l}\text { Always follows the } \\
\text { recommendations }\end{array}$ & $\mathbf{M}$ & SD \\
\hline $\begin{array}{l}\text { If the patient is unable to communicate adequately and I do not know the patient, I verify } \\
\text { the identity from the wristband. }\end{array}$ & $35.77 \%$ & 1.64 & 1.753 \\
\hline $\begin{array}{l}\text { When calculating a dosage my colleague double-checks the calculation independently and } \\
\text { the results are compared. }\end{array}$ & $40.85 \%$ & 0.98 & 1.146 \\
\hline $\begin{array}{l}\text { When administering the medication to the patient I check that the medication that I am } \\
\text { giving equates with the medication in the prescription. }\end{array}$ & $48.40 \%$ & 0.90 & 1.074 \\
\hline $\begin{array}{l}\text { When dispensing or preparing medication I read the name of the medication carefully from } \\
\text { the labeling, even for a familiar medication. }\end{array}$ & $62.90 \%$ & 0.36 & 0.697 \\
\hline $\begin{array}{l}\text { When dispensing medication another nurse double-checks the medication prior to } \\
\text { administering it to the patient. }\end{array}$ & $64.40 \%$ & 0.61 & 1.037 \\
\hline I verify the dosage before giving the medication to the patient. & $64.84 \%$ & 0.56 & 0.919 \\
\hline $\begin{array}{l}\text { When dispensing medication another nurse double-checks the dosage prior to } \\
\text { administering it to the patient. }\end{array}$ & $68.29 \%$ & 0.54 & 1.013 \\
\hline $\begin{array}{l}\text { When administering medication to a patient, I verify the suitable route for administration } \\
\text { from the labeling. }\end{array}$ & $68.70 \%$ & 0.47 & 0.828 \\
\hline $\begin{array}{l}\text { When dispensing or preparing medication I read the name of the medication carefully from } \\
\text { the prescription, even for a familiar medication. }\end{array}$ & $70.70 \%$ & 0.71 & 1.140 \\
\hline $\begin{array}{l}\text { I verify the dosage of the medication from the prescription or other documents before } \\
\text { dispensing, even if I know the patient well. }\end{array}$ & $77.64 \%$ & 0.31 & 0.723 \\
\hline I verify the identity of the patient before administering medication. & $79.27 \%$ & 0.43 & 0.974 \\
\hline Before preparing the medication, I verify the route of administration from the prescription. & $80.89 \%$ & 0.22 & 0.552 \\
\hline $\begin{array}{l}\text { I also verify the name of the patient from the medicine card of the medicine tray or the pill } \\
\text { dispenser. }\end{array}$ & $82.32 \%$ & 0.27 & 0.740 \\
\hline $\begin{array}{l}\text { I verify the strength of the medicine from the labeling before dispensing, even for familiar } \\
\text { medication. }\end{array}$ & $89.00 \%$ & 0.11 & 0.445 \\
\hline I carefully verify the units from the prescription and the labeling. & $89.84 \%$ & 0.10 & 0.388 \\
\hline
\end{tabular}

Table 4. Significance of correlations between scores of the categories and medication calculation skills and knowledge of both pharmacology and infection control

\begin{tabular}{llll}
\hline & $\begin{array}{l}\text { Knowledge of } \\
\text { Pharmacology }\end{array}$ & $\begin{array}{l}\text { Knowledge of } \\
\text { Infection control }\end{array}$ & $\begin{array}{l}\text { Calculation } \\
\text { skills }\end{array}$ \\
\hline Safety Checks & $p<.001$ & $p<.001$ & $p<.05$ \\
Monitoring & $p<.001$ & $p<.001$ & $p<.001$ \\
Documentation & $p<.001$ & $p<.05$ & $p>.05$ \\
\hline
\end{tabular}

\subsection{Monitoring}

More than half of the participants (59\%) claimed to monitor effects of administered medication thoroughly. However, around $40 \%$ of the participants deviated from the guidelines 'if necessary'. The biggest deviation was found in responses to the item Before administering medication I evaluate the need for the medication with respect to the condition of the patient (e.g. insulin, diuretics, medication for high blood pressure). Only $30.9 \%$ evaluated the patient's condition with respect to medication prior to administration of medication. Around half of the participants (48.2\%) continuously monitored possible adverse and side effects of the patient and a similar percentage (51.8\%) frequently measured the blood pressure of patients on medication for high blood pressure. The pain of patients on pain medication and blood glucose levels of patients with diseases affecting them were reportedly assessed by higher percentages: 74 and $81.5 \%$, respectively (see Table 5).

No connection was found between the results in the monitoring category and participants' age, working experience or occupational group. However, participants who assessed their performance in the medication management process highly (>9.0) obtained significantly better scores in the monitoring category $(p<.001)$ than those with poorer self-reported performance $(<8.7)$.

In addition, extremely significant correlations were found between scores in the monitoring category and participants' evaluations of their medication calculation skills and knowledge of both pharmacology and infection control, in comparisons of the highest and lowest quartiles $(p<.001)$. There were also very significant differences $(p<.01)$ in reported pharmacology and infection control competences 
between the highest and third quartiles. In sum, participants' self-reported mastery of pharmacology and infection control knowledge was tightly correlated with their monitoring scores (see Table 4).

\subsection{Documentation}

Most of the nurses (75\%) reportedly maintained good practice in medication documentation management (mean Likert score: $0.3 \pm 0.4$ ). However, more than half did not document effects of medication $(53.25 \%)$ or reasons for late adminis- tration of medication (57.3\%). Most documented medication after its administration (89\%) and both reasons for and doses of PRN medication (94.3\%) (see Table 6).

There were no significant associations between documentation scores and participants' frequency of medication actions, occupational group, working experience or age. However, very significant positive correlations were detected $(p<.001)$ between documentation scores and knowledge of both pharmacology and infection control (see Table 4).

Table 5. Items of the monitoring category

\begin{tabular}{|c|c|c|c|}
\hline Item & $\begin{array}{l}\text { Always follows the } \\
\text { recommendations }\end{array}$ & Mean & SD \\
\hline $\begin{array}{l}\text { Before administering medication I evaluate the need for the medication with respect to } \\
\text { the patient's condition (e.g. insulin, diuretics, medication for high blood pressure). }\end{array}$ & $30.9 \%$ & 1.12 & 0.983 \\
\hline I continuously monitor possible adverse and side effects. & $48.17 \%$ & 0.67 & 0.778 \\
\hline $\begin{array}{l}\text { I frequently measure the patient's blood pressure, especially when the patient is on } \\
\text { medication that affects high blood pressure. }\end{array}$ & $51.83 \%$ & 0.62 & 0.747 \\
\hline $\begin{array}{l}\text { I monitor the patient's mental status, especially if s/he uses medication for mental } \\
\text { problems. }\end{array}$ & $58.74 \%$ & 0.49 & 0.660 \\
\hline I monitor whether the medication has expected effects on the patient. & $59.15 \%$ & 0.45 & 0.595 \\
\hline I monitor effects of the medication based on results of measurements I do for the patient. & $63.40 \%$ & 0.44 & 0.690 \\
\hline $\begin{array}{l}\text { I assess and monitor the patient's pain and the pain medication's sufficiency if s/he is on } \\
\text { pain medication. }\end{array}$ & $74.00 \%$ & 0.29 & 0.519 \\
\hline I frequently measure the patient's blood glucose level if s/he has a disease that affects it. & $81.50 \%$ & 0.19 & 0.427 \\
\hline
\end{tabular}

Table 6. Items in the documentation category

\begin{tabular}{|c|c|c|c|}
\hline Item & $\begin{array}{l}\text { Always follows the } \\
\text { recommendations }\end{array}$ & Mean & SD \\
\hline I also document effects of the medication (e.g. whether pain medication gives relief). & $53.25 \%$ & 0.57 & 0.706 \\
\hline If I administer medication late I also document the reason for the event. & $57.30 \%$ & 0.63 & 0.859 \\
\hline I document all the events concerning the medication process in the patient's records. & $76.80 \%$ & 0.32 & 0.687 \\
\hline In case of omission, I document the reason for it. & $79.47 \%$ & 0.24 & 0.532 \\
\hline I do not document medication before confirming that the patient has taken it. & $89.00 \%$ & 0.15 & 0.519 \\
\hline $\begin{array}{l}\text { When documenting a PRN medication I also document the reason for and dosage of the } \\
\text { medication. }\end{array}$ & $94.30 \%$ & 0.07 & 0.331 \\
\hline
\end{tabular}

\section{Discussion}

\subsection{Safety checks}

Routine safety checks during the medication management process are known to increase patient safety and reduce frequencies of errors, but guidelines are often violated. ${ }^{[20,22]}$ As already mentioned, Jones \& Treiber $^{[20]}$ found that most nurses they surveyed rated statement 'Did not follow the 5 rights' as major contributory factors to medication errors. Also according to the study of Härkänen et al. ${ }^{[17]}$ the use of 5 rights check list during the medication process is recommended. Accordingly, although most of the participants

Published by Sciedu Press in this study self-reportedly maintained good practices in confirming that the right patient received the right dose of the right medication at the right time, a third of them ignored some of the safety checks sometimes when administering medication.

In addition, although most participants indicated that they consistently confirmed patients' identity in some way, only half always used full names of patients they did not know before administering medication, and a minority asked the patient to give his/her name. About half of the participants felt that they did not need to identify patients verbally be- 
cause they already knew them. Dementia was another commonly indicated reason for neglecting verbal identification. As many patients in long-term elderly care wards suffer from dementia, alternative identity control measures should be considered. Use of wristbands is recommended, but they are rarely used (explaining why a low percentage of participants used them to check patients' identities). The results highlight a clear need for improvement as, for example, Härkänen et al. ${ }^{[6]}$ found that in most medication errors recorded in a Finnish hospital the patient was not identified at all. Similarly, Kelly et al. ${ }^{[13]}$ found that there were inadequacies in the identification process in routine medication administration of patients in Australia.

Another deficiency in the participants' self-reported practice is that less than half asked another nurse to double check medication calculations, and around $35 \%$ did not consistently double-check before administering medication to patients. This clearly violates recommendations. ${ }^{[19]}$ In most longterm elderly care wards in Finland automated dispensing systems are used, and several nurses justified the violation by stating that medications in packages they used had already been checked (mainly when they were brought from the pharmacy), so there was no need for further checking before giving them to the patients. Also, Härkänen et al. ${ }^{[15]}$ found that medication was not double-checked in some of the medication administration incidents they addressed. The results suggest that safety checks should potentially be improved during the dispensing, preparation and administration of medication.

\subsection{Monitoring}

Monitoring is an essential part of medication process, as it is crucial for recognizing and identifying causes of problems, and recorded information must be forwarded to everyone involved in patient's care as well as patients themselves (or relatives). However, $41 \%$ of the participants did not always monitor effects of administered medication properly; medication was often given without assessment of patients' conditions and/or appropriate measurements (although pain and blood glucose levels were relatively well monitored, according to the nurses). This clearly requires attention as, for example, Dilles et al. ${ }^{[16]}$ found that deficiencies in monitoring medication effects were important contributors to lack of knowledge of side effects.

For example, pharmacological knowledge is essential for assessing patients before administering medication, administering medication safely and effectively, evaluating the effectiveness of administered medication, counselling patients and so on. ${ }^{[21,30]}$ However, Dilles et al. ${ }^{[28]}$ found that nursing students have limited knowledge of pharmacology and medication calculation skills, even just before graduation, so these deficiencies should be addressed in early stages of nursing education. ${ }^{[29]}$ Accordingly, responses of participants' responses in this study indicated that their monitoring performance was correlated with their perceived medication calculation skills and perceived knowledge of both pharmacology and infection control. Moreover, very significant correlation was detected between these variables and their scores in monitoring. A conclusion is that in order to monitor the effects proficiently, a nurse needs both theoretical and practical competence, which are closely associated.

\subsection{Documentation}

According to their responses, only about half of the nurses documented effects of the medication, e.g., whether the pain medication gave relief. Three quarters reportedly assessed and monitored patients' pain and the sufficiency of pain medication for patients receiving it. However, less than half documented reasons for late medication administration. Most stated that they documented administrations after confirming that patients had taken the medicine. However, Kelly \& Wright ${ }^{[12]}$ found that medicine was sometimes recorded as taken, even when it was left on a patient's table.

No association between the results and working experience was detected. Similar absence of effects of experience on nurses' self-assessed competence in intravenous infusion and drug therapy ${ }^{[35]}$ and general nursing competence ${ }^{[36]}$ has been recorded. In this study, no correlations between occupational group and scores of any categories were detected either.

In sum, the results support the conclusion by Härkänen et al. ${ }^{[17]}$ that more attention and caution are required in medication administration practices to reduce errors. There should be continuous reminders of this need in wards, and support from the management. One third of the participants gave themselves a rating of eight or less when self-assessing how well they implement safe medication principles in their work, and there was an association between these self-assessments and participants' responses to items in all three categories. Every time a nurse ignores a safety check during the process, it presents the possibility for a medication error and adverse event. Various medication management protocols have been formulated to improve patient safety, and a set covering every activity should be rigorously implemented. In addition, experienced nurses should encourage recently graduated nurses to comply with medication protocols and stress their importance for safe, high quality patient care. ${ }^{[21]}$ Monitoring must be included, and documentation to ensure that the quality and outcome of the process can be continuously evaluated. All actions that improve medication safety also enhance its effectiveness. For example, pharmacological knowledge is 
an important part of medication competence, ${ }^{[28-30]}$ so addressing this knowledge in early stages of nurses' education is important. In this study, participants' scores in all three categories were correlated with their medication calculation skills and knowledge of both pharmacology and infection control. Thus, all of these areas should be deeply considered in both pre-qualification nursing education and continuing education.

\subsection{Limitations}

The study has several limitations that should be taken into account. In the scale development stage of the study a panel of experts was used to assess the validity of the content. Each member of the panel received the same written instructions. The panel provided important information on the content and clarity of the developed scale. After modification based on the panel's assessment the content validity scores, I-CVI and CVI/Ave, ${ }^{[32]}$ were excellent. However, the procedure was inevitably subject to the usual limitations of panel-based content validation.

In the pilot study it was noticed that there was so little variation in the responses that the reliability according to Cronbach's alpha was low due to the weak variance of the sum variable used to calculate it. Thus, use of this statistic for assessing the scale's internal consistency was inappropriate, because in order to improve it sufficiently essential items may have had to be excluded, which would have weakened its validity. Hence, Tarkkonen's Rho (which is more versatile) was used to evaluate its reliability. ${ }^{[37-39]}$ However, in this study both Cronbach's alpha and Tarkkonen's Rho values are presented (see Table 1) and they are satisfactory.

The response rate in the pilot study was low (24\%), so no statistical analysis of the construct validity at that stage was possible. In this study the response rate was much better (39.4\%), and satisfactory as response rates of online network surveys in international studies are typically about 30\%. ${ }^{[40]}$ It is a limitation of this study that no non-responder analysis was done due to lack of relevant data. However, the age and occupational distributions of the participants in this study represent closely the average in long-term elderly care in Finland. Response rates from some of the wards were over $90 \%$ while the lowest were less than $30 \%$. In total, 492 nurses returned questionnaires; a satisfactory number for the statistical analysis. A reminder was sent to the superiors of the wards four times during the data collection period, to

\section{REFERENCES}

[1] Fialova D, Topinkova E, Gambassi G, et al. Potentially inappropriate medication use among elderly home care patients in Europe. The give the entire target population adequate opportunity to participate in the study. However, it was not confirmed whether the superiors forwarded the link to the questionnaire to the staff, or whether s/he motivated the staff to participate even during busy times. There were also some problems with the web-based data collection program, for example cutting of the connection, which may have affected some participants' motivation. However, the participants had to answer every item to complete the questionnaire, so there were no missing data, which facilitated the analysis. A few participants complained that it took too long to complete during busy days, but this may have been partly because the open questions were answered surprisingly thoroughly.

Thorough answers to all 109 open questions show that the participants concentrated on the survey. No deterioration could be seen in data quality towards the end of the survey. A few questions, which measure the same issue as another question in reverse form, were included in the scale in order to avoid biased responses. ${ }^{[41]}$ In addition, if the participants had embellished their answers, no deviation from the recommendations presented in this study could be detected. It can therefore be concluded that the results of this study are indicative of the implementation of the subject studied.

\section{Conclusion}

The results of this study indicate that most nurses maintain satisfactory practices and follow guidelines in performing safety checks, monitoring the effects of medication and documenting all activities. However, any deviation from the guidelines presents the possibility for an error. On that account, there is a clear need to enhance all these aspects to improve patient safety. The quality of the participants' medication practices correlated with their medication calculation skills and knowledge of both pharmacology and infection control. Thus, these contents in nurses' pre-qualification education and continuing education should be improved. The nurses also need to understand why it is important to perform medication safety checks, monitor effects of medication and properly document all steps of the process. Attitudinal and ethical aspects of safe medication management should be emphasized. Elderly people are particularly prone to medication errors and nurses are the key professionals to prevent them.

\section{Conflicts of InTEREST Disclosure}

The authors declare that there is no conflict of interest.

Journal of the American Medical Association. 2005 Mar; 293(11): 1348-1358. https://doi.org/10.1001/jama.293.11.1348

[2] Fialova D, Onder G. Medication errors in elderly people: Contribut- 
ing factors and future perspectives. British Journal of Clinical Pharmacology. 2009 Jun; 67(6): 641-645. https ://doi .org/10.111 $1 / j \cdot 1365-2125.2009 .03419 \cdot x$

[3] Ahonen J. Drug use in elderly persons: Inappropriate medication and drug interactions. University of Eastern Finland, Faculty of Health Sciences. Publications of the University of Eastern Finland. 2011. Dissertations in Health Sciences 66.

[4] Institute of Medicine. Preventing Medication Errors. Washington, DC: National Academy Press; 2007.

[5] Institute of Medicine. To Err Is Human: Building a Safer Health System. Washington, DC: The National Academies Press; 2000.

[6] Härkänen M, Turunen H, Saano S, et al. Detecting medication errors: Analysis based on a hospital's incident reports. International Journal of Nursing Practice. 2015 Apr; 21(2): 141-146. https://doi.org/10.1111/ijn.12227

[7] Lisby M, Nielsen L, Mainz J. Errors in the medication process: frequency, type, and potential. International Journal for Quality Health Care. 2005 Feb; 17(1): 15-22. https://doi.org/10.1093/intq $\mathrm{hc} / \mathrm{mzi015}$

[8] Van Den Bemt P, Idzinga J, Robertz H, et al. Medication administration errors in nursing homes using an automated medication dispensing system. Journal of the American Medical Informatics Association. 2009 Jul-Aug; 16(4): 486-92. https ://doi .org/10 $.1197 /$ jamia.M2959

[9] Ernawati D, Lee Y, Hughes J. Nature and frequency of medication errors in a geriatric ward: an Indonesian experience. Therapeutics and Clinical Risk Management, 2014 Jun 3; 10: 413-21. https://doi.org/10.2147/TCRM. S61687

[10] Hughes R, Ortiz E. Medication errors: Why they happen and how they can be prevented. American Journal of Nursing. 2005 Mar; 105(3): 14-24. https://doi.org/10.1097/00000446-2 00503001-00005

[11] Joanna Briggs Institute. Strategies to reduce medication errors with reference to older adults. Nursing Standards. 2006 Mar; 4(1): 2-41.

[12] Kelly J, Wright D. Medicine administration errors and their severity in secondary care older persons' ward: a multi-center observational study. Journal of Clinical Nursing. 2012 Jul; 21(13-14): 1806-15. https://doi.org/10.1111/j.1365-2702.2011.03760.x

[13] Teunissen R, Bos J, Pot H, et al. Clinical relevance of and risk factors associated with medication administration time errors. American Journal of Health-System Pharmacy. 2013 Jun 15; 70(12): 1052-6. https://doi.org/10.2146/ajhp120247

[14] Kelly T, Roper C, Elsom S, et al. Identifying the 'right patient': Nurse and consumer perspectives on verifying patient identity during medication administration. International Journal of Mental Health Nursing. 2011 Oct; 20(5): 371-9. https://doi.org/10.1111/j. 1447-0349.2010.00739.x

[15] Härkänen M, Ahonen J, Kervinen M, et al. The factors associated with medication errors in adult medical and surgical inpatients: A direct observation approach with medication records reviews. Scandinavian Journal of Caring Science. 2015 Jun; 29(2): 297-306. https://doi.org/10.1111/scs.12163

[16] Dilles, T, Elseviers M, Rompaey B, et al. Barriers for nurses to safe medication management in nursing homes. Journal of Nursing Scholarship. 2011 Jun; 43(2): 171-80. https://doi.org/10.1111/j. 1547-5069.2011.01386.x

[17] Härkänen M, Saano S, Turunen H, et al. Terveydenhuollon henkilöstön näkemykset lääkityspoikkeamien estämisestä erikoissairaanhoidossa. Hoitotiede. 2013; 25: 49-61.

[18] Pape T. Applying airline safety practices to medication administration. Medical-Surgical Nursing. 2003 Apr; 12(2): 77-93; quiz 94.
[19] Armitage G. The risks of double checking. Nursing Management. 2009 May; 16(2): 30-5. https://doi.org/10.7748/nm2009.0 $5 \cdot 16 \cdot 2 \cdot 30 . c 7012$

[20] Jones J, Treiber L. When the 5 rights go wrong. Medication errors from the nursing perspective. Journal of Nursing Care Quality. 2010 Jul-Sep; 25(3): 240-7. https://doi.org/10.1097/NCQ.0b013e $3181 \mathrm{~d} 5 \mathrm{~b} 948$

[21] Manias E. Pharmacology content in undergraduate nursing programmes: Is there enough to support nurses providing safe and effective care? International Journal of Nursing Studies. 2009 Jan; 46(1): 1-3. https://doi.org/10.1016/j.ijnurstu. 2008.06.002

[22] Kim J, Bates D. Medication administration errors by nurses: adherence to guidelines. Journal of Clinical Nursing. $2013 \mathrm{Feb}$; 22(34): 590-8. https://doi.org/10.1111/j.1365-2702.2012.0 $4344 . x$

[23] Wilson D, DiVito-Thomas P. The sixth right of medication administration. Right response. Nurse Educator. 2004 Jul-Aug; 29(4): 131-132. https://doi.org/10.1097/00006223-200407000-00001

[24] Elliot M, Liu Y. The nine rights of medication administration: An overview. British Journal of Nursing. 2010 Mar; 19(5): 300-5. https://doi.org/10.12968/bjon.2010.19.5.47064

[25] Edwards S, Axe S. The 10 'R's of safe multidisciplinary drug administration. Nurse Prescribing. 2015 Aug; 13(8): 398-406. https : //doi.org/10.12968/npre.2015.13.8.398

[26] National Institute for Health and Welfare. Turvallinen lääkehoito: Opas lääkehoitosuunnitelman tekemiseen terveydenhuollossa. Tampere, Finland: Juvenes Print - Suomen Yliopistopaino Oy; 2015.

[27] Sulosaari V, Suhonen R, Leino-Kilpi H. An integrative review of the literature on registered nurses' medication competence. Journal of Clinical Nursing. 2011 Feb; 20(3-4): 464-78. https ://doi.org/ $10.1111 / j \cdot 1365-2702.2010 .03228 \cdot x$

[28] Dilles T, Stichele R, Bortel L, et al. Nursing students' pharmacological knowledge and calculation skills. Ready to practice? Nurse Education Today. 2011 Jul; 31(5): 499-505. https ://doi.org/10 $.1016 / j$.nedt. 2010.08.009

[29] Meechan R, Mason V, Catling J. The impact of an integrated pharmacology and medicines management curriculum for undergraduate adult nursing students on the acquisition of applied drug/pharmacology knowledge. Nurse Education Today. 2011 May; 31(4): 383-9. https://doi.org/10.1016/j.nedt.2010.07.0 11

[30] Adhikari R, Tocher J, Smith P, et al. A multi-disciplinary approach to medication safety and the implication for nursing education and practice. Nurse Education Today. 2014 Feb; 34(2): 185-90. https://doi.org/10.1016/j.nedt. 2013.10.008

[31] Ignatavicius D. Asking the right questions about medication safety. Learn how to get answers you need to safeguard your practice. Nursing. 2000 Sep; 30(9): 51-54. https://doi.org/10.1097/0015 2193-200030090-00019

[32] Karttunen M, Kääriäinen M, Jokelainen J, et al. Ikääntyneiden turvallinen lääkehoito - mittarin kehittämisprosessi. Gerontologia. 2017 Jun; 31(2): 87-99. https://doi.org/10.23989/gerontologi a. 63086

[33] Karttunen M, Sneck S, Jokelainen J, et al. Nurses' self-assessments of adherence to guidelines on safe medication preparation and administration in long-term elderly care. Scandinavian Journal of Caring Science. 2019. In Press.

[34] DeVellis R. Scale Development: Theory and Applications. 2nd ed. Thousand Oaks, CA. Sage Publications; 2003.

[35] Sneck S, Isola A, Saarnio R. Nurses' assessment of their competence in intravenous infusion and drug therapy and their views on the confirmation of their competence. Hoitotiede. 2013; 25(4): 253-265. 
[36] Mäkipeura J, Meretoja R, Virta-Helenius M, et al. Sairaanhoitaja neurologisessa toimintaympäristössä. Ammatillinen pätevyys, toiminnan tiheys ja täydennyskoulutuksen haasteet. Hoitotiede. 2007; 10(3): 152-162.

[37] Tarkkonen L, Vehkalahti K. Measurement errors in multivariate measurement scales. Journal of Multivariate Analysis. 2005 Sep; 96(1): 172-189. https://doi .org/10.1016/j . jmva. 2004.09.007

[38] Vehkalahti K. Reliability of measurement scales. Tarkkonen's general method supersedes Cronbach's alpha. 2000. Helsingin yliopisto, tilastotieteenlaitos. Doctoral theses.

[39] Vehkalahti K, Puntanen S, Tarkkonen L. Estimation of reliability: a better alternative for Cronbach's alpha. Elsevier Science. 2006 Sep; $1-20$.

[40] Sue V, Ritter L. Conducting Online Surveys. Sage Publications, USA. 2007.

[41] Suárez-Alvarez J, Pedrosa I, Lozano L, et al. Using reversed items in Likert scales: A questionable practice. Psicothema. 2018 May; 30(2): 149-158. 